\title{
Influence of the features of the unsaturated zone on the air injection method in a slope
}

Wei Xie BEng

PhD candidate, College of Civil Engineering and Architecture, Zhejiang University, Hangzhou, Zhejiang, P. R. China (Orcid:0000-0003-1444-2873)

\section{Hongyue Sun PhD}

Professor, Ocean College, Zhejiang University, Zhoushan, Zhejiang, P. R. China (corresponding author: shy@zju.edu.cn)

Zhenlei Wei PhD

Research Fellow, College of Civil Engineering and Architecture,

Zhejiang University, Hangzhou, Zhejiang, P. R. China
Yuequan Shang $\mathrm{PhD}$

Professor, College of Civil Engineering and Architecture, Zhejiang University, Hangzhou, Zhejiang, P. R. China

Xin Yan BEng

PhD candidate, Ocean College, Zhejiang University, Zhoushan, Zhejiang, P. R. China

The drainage of groundwater is essential to slope stabilisation in both potential and existing landslides. Air injection is a new method for slope drainage that aims to control rapid rises in the groundwater level by creating an artificial unsaturated zone with low permeability. The interception ratio, reflecting the effectiveness of the air injection method in intercepting groundwater, is defined in this paper and the effects of the length and hydraulic conductivity of the unsaturated zone on the interception ratio are studied through theoretical analysis, physical tests and numerical simulations. The results show that, in the initial stage, the interception ratio increases quickly with an increase in the length of the unsaturated zone. The interception ratio then gradually stabilises, with the stable value depending on the decrease in hydraulic conductivity of the unsaturated zone. The findings reported in this paper are important for improving the design of the air injection method.

\section{Notation}

$A_{0} \quad$ cross-sectional seepage area before air injection

$A_{\mathrm{P}} \quad$ cross-sectional seepage area after air injection

$a, m, n \quad$ curve fitting parameters

$H_{\mathrm{w}} \quad$ total head of water

$h_{\text {up }} \quad$ groundwater level at upstream boundary of slope

$i \quad$ hydraulic gradient

$k \quad$ equivalent hydraulic conductivity after air injection

$k_{0} \quad$ saturated hydraulic conductivity of recharge zone

$k_{\mathrm{a}} \quad$ estimated air conductivity at a particular degree of saturation

$k_{\text {dry }} \quad$ air conductivity of dry soil

$k_{\mathrm{P}} \quad$ hydraulic conductivity of unsaturated zone

$k_{\mathrm{s}} \quad$ saturated hydraulic conductivity

$k_{\mathrm{w}} \quad$ hydraulic conductivity

$L \quad$ length of air injection

$L_{0} \quad$ length of recharge zone

$L_{\mathrm{P}} \quad$ length of unsaturated zone

$m_{\mathrm{w}} \quad$ slope of volumetric water content function

$P \quad$ air injection pressure

$Q_{0} \quad$ groundwater seepage before air injection

$Q_{\mathrm{P}} \quad$ groundwater seepage after air injection

$Q_{\mathrm{w}} \quad$ applied water boundary flux

$S_{\mathrm{w}} \quad$ degree of saturation

$T \quad$ temperature

$u_{\mathrm{a}} \quad$ pore air pressure

$u_{\mathrm{w}} \quad$ pore water pressure

$\Delta H \quad$ total head loss

$\Delta h_{0} \quad$ head loss in groundwater recharge zone

$\Delta h_{\mathrm{P}} \quad$ head loss in unsaturated zone

$\gamma_{\text {oa }} \quad$ unit weight of air in dry conditions

$\gamma_{\mathrm{w}} \quad$ unit weight of water

$\begin{array}{ll}\lambda & \text { interception ratio } \\ \theta_{\mathrm{a}} & \text { volumetric air content } \\ \theta_{\mathrm{r}} & \text { residual volumetric water content } \\ \theta_{\mathrm{s}} & \text { saturated volumetric water content } \\ \theta_{\mathrm{w}} & \text { volumetric water content } \\ \rho_{\mathrm{a}} & \text { density of air } \\ \rho_{\mathrm{oa}} & \text { density of air in dry conditions } \\ \phi & \text { matric suction }\end{array}$

\section{Introduction}

Rainfall is a key factor in landslides that occur throughout the world (Zhang et al., 2011). For rainfall-induced landslides, controlling the rapid increase in groundwater level in the slope is a significant component of slope stabilisation (Zhou et al., 2016). Current drainage techniques include interception trenches, diversion ditches, horizontal drains, drainage tunnels and so on (Schuster and Highland, 2007). However, owing to terrain constraints, debatable long-term reliability or timeconsuming construction, these measures do not always ensure the fast drainage of groundwater (Cotecchia et al., 2016; Rahardjo et al., 2003; Sun et al., 2010). Therefore, a drainage measure that can achieve rapid drainage and be easily constructed is urgently required for rainfall-induced landslide mitigation.

Unsaturated soil is a multi-phase system that contains solid material, water and air, and the configuration of the pore water and air has a significant effect on the hydraulic conductivity of the soil (Fredlund, 2006; Zhang and Fredlund, 2015). Studies have shown that entrapped air can reduce the infiltration rate and the hydraulic conductivity of unsaturated 
soil declines significantly with any decrease in soil saturation (Nakajima et al., 2016; Neyshabouri et al., 2013; Zhan et al., 2014). Compressed air has been successfully used to exclude pore water and can be stored in geological formations in engineering applications such as underground gas storage reservoirs (Castelletto et al., 2013) and shield tunnelling with compressed air support (Allenby and Kilburn, 2015). In addition, soil desaturation by air injection has been used to remediate liquefaction in recent years (Okamura et al., 2011; Zeybek and Madabhushi, 2018), proving that air injection underneath an existing structure is feasible.

Based on these studies, Sun and Shang (2009) proposed a new method for slope drainage - the air injection method. Through the injection of compressed air into soil, this method attempts to control rapid increases in underground water levels by constructing an artificial unsaturated area with low permeability. Some basic research has been carried out since this method was proposed and the feasibility of the method has been validated in preliminary investigations. For instance, in a tank model test, Liu et al. (2014) found that air injection in soil significantly decreases the rate of wet-front development and the infiltration rate. Du et al. (2013) proposed a formula for calculating the minimum and maximum injection pressure based on theoretical analysis. Xie et al. (2018a) investigated the influence of the air injection method on groundwater level variations and studied the formation process of the low-permeability unsaturated zone based on a large-scale slope model (Xie et al., 2018b).

In previous physical model tests, the number of injection points and the range of the unsaturated zone formed by air injection were limited by the small model sizes. The influence of the characteristics of unsaturated zones on the effectiveness of the air injection method in intercepting groundwater has not been analysed in depth, and there remains a need for further analyses on the design of these unsaturated zones to enhance the foundations of the air injection method.

A theoretical analysis of the effectiveness of the air injection method in intercepting groundwater and the features of the unsaturated zone is presented in this paper. The results of several air injection tests based on a physical model of a silty clay slope are reported and the effects of the features of the unsaturated zone on the air injection method are analysed using numerical simulations.

\section{The air injection method}

The air injection method creates an artificial unsaturated zone with low permeability by injecting compressed air into a slope, as shown in Figure 1. The method aims to intercept upstream groundwater flowing towards a potential landslide. The theoretical foundation of the air injection method is that the hydraulic conductivity of the unsaturated soil is reduced as the water content decreases (Fredlund, 2006). Air movement can expel groundwater and significantly reduce infiltration on the slope surface. Moreover, air injection can reduce the permeability in the vicinity of a potential sliding zone, thus intercepting the seepage of upstream groundwater to the potential landslide area. In engineering practice, some landslides are triggered by intense rainfall, which causes the groundwater level to rise through infiltration on the slope surface and subsurface water movement from higher elevations. The latter is the major source of the replenishment of groundwater resources for landslides where a large catchment area exists upstream. Considering the complexity of simultaneously analysing the interception of upstream groundwater and the interception of slope infiltration following air injection, these two aspects are analysed separately. The paper first discusses the role of the unsaturated zone as a waterproof curtain and then analyses the effect of air injection on infiltration into a slope.

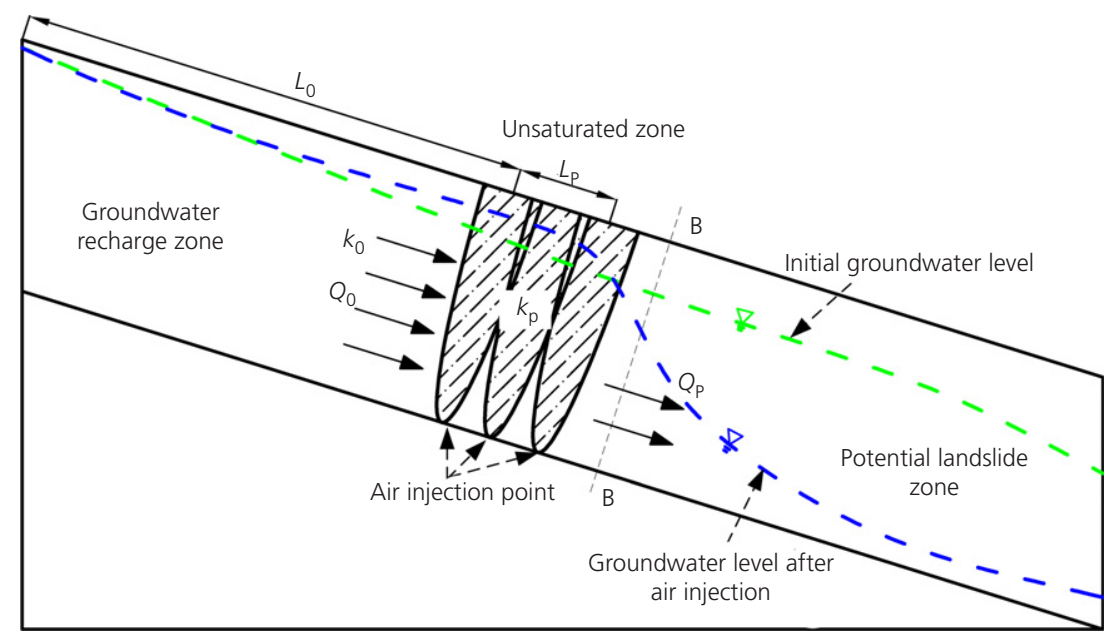

Figure 1. Schematic illustration of the air injection method 
The characteristics of the unsaturated zone formed by air injection, such as geometric features and permeability, are important design parameters. According to studies on air sparging as a technique for the clean-up of contaminated soils, the shape of the unsaturated zone is usually approximated by either a parabolashaped zone (Catney and Lynch, 2001; Semer et al., 1998) or a cone-shaped zone (Lundegard and Andersen, 1996; Semer et al., 1998). The dimensions and permeability of the unsaturated zone depend on factors such as the injection pressure, the number and depth of injection points and the properties of the soil.

Based on a two-dimensional (2D) design of the air injection method (Figure 1), some parameters that characterise the dimensions of the unsaturated zone can be defined and the effectiveness of the air injection method in intercepting groundwater can be analysed. As shown in Figure 1, the slope is divided into the following three zones after implementation of the air injection method.

- Groundwater recharge zone upstream of the injection point. The main parameters are the length of the recharge zone $\left(L_{0}\right)$, the saturated hydraulic conductivity of the recharge zone $\left(k_{0}\right)$ and groundwater seepage before air injection $\left(Q_{0}\right)$.

- Unsaturated zone formed by air injection. The main parameters are the length of the unsaturated zone $\left(L_{\mathrm{P}}\right)$ and hydraulic conductivity of the unsaturated zone $\left(k_{\mathrm{P}}\right)$.

- Potential landslide zone or groundwater control zone downstream of the injection point. The main parameter is the groundwater seepage after air injection $\left(Q_{\mathrm{P}}\right)$.

The interception ratio $(\lambda)$ evaluates the effectiveness of the air injection method in intercepting groundwater

1. $\lambda=\frac{Q_{0}-Q_{\mathrm{P}}}{Q_{0}}$

The value of $\lambda$ ranges between 0 and $1 ; \lambda=0$ indicates that the air injection method is ineffective and while values closer to 1 indicate better effectiveness of the method in intercepting upstream groundwater.

Groundwater seepage before and after air injection through section B-B downstream of the unsaturated zone (see Figure 1), when the seepage is basically in a stable state, can be expressed as

2. $Q_{0}=k_{0} i A_{0}$

3. $Q_{\mathrm{P}}=k i A_{\mathrm{P}}$

where $i$ is the hydraulic gradient, which is assumed to remain unchanged before and after air injection, $A_{0}$ is the cross-sectional seepage area of section $\mathrm{B}-\mathrm{B}$ before air injection, $A_{\mathrm{P}}$ is the cross-sectional seepage area of section B-B after air injection and $k$ is the equivalent hydraulic conductivity in the range $L_{0}+L_{\mathrm{P}}$ after air injection.

It is assumed that $A_{0}=A_{\mathrm{P}}$. The seepage process is a threedimensional problem. To simplify the analysis, the seepage process is simplified into a $2 \mathrm{D}$ problem and the effects of area change are neglected. In fact, the injected air occupies some volume of the soil pores. Therefore, the seepage area will decrease after air injection. In other words, $A_{\mathrm{P}}<A_{0}$. Considering that it is difficult to determine the relationship between $A_{0}$ and $A_{\mathrm{P}}$ accurately, it is assumed that $A_{0}=A_{\mathrm{P}}$. This assumption results in a calculated value of $Q_{\mathrm{P}}$ that is larger than the actual value, but this is a conservative assumption considered to be acceptable in this study.

The calculation of $k$ is based on flow normal to the multi-layer soil (Budhu, 2010). For flow normal to the multi-layer soil, the total head loss in the soil mass $(\Delta H)$ is the sum of the head losses in each layer

\section{4. $\Delta H=\Delta h_{0}+\Delta h_{\mathrm{P}}$}

where $\Delta h_{0}$ is the head loss in the groundwater recharge zone and $\Delta h_{\mathrm{P}}$ is the head loss in the unsaturated zone. The velocity in each layer is the same. From Darcy's law

5. $k \frac{\Delta H}{L_{0}+L_{\mathrm{P}}}=k_{0} \frac{\Delta h_{0}}{L_{0}}=k_{\mathrm{P}} \frac{\Delta h_{\mathrm{P}}}{L_{\mathrm{P}}}$

Solving Equations 4 and 5 leads to

6. $\quad k=\frac{L_{0}+L_{\mathrm{P}}}{\left(L_{0} / k_{0}\right)+\left(L_{\mathrm{P}} / k_{\mathrm{P}}\right)}$

Therefore, the interception ratio $\lambda$ can be expressed as

7. $\lambda=\frac{\left(k_{0} / k_{\mathrm{P}}\right)-1}{\left(k_{0} / k_{\mathrm{P}}\right)+\left(L_{0} / L_{P}\right)}$

In Equation $7, k_{0} / k_{\mathrm{P}}$ represents the magnitude of the decrease in hydraulic conductivity of the unsaturated zone and $L_{\mathrm{P}} / L_{0}$ represents the dimension of the unsaturated zone. The interception ratio is affected by both the permeability and the dimensions of the unsaturated zone.

Figure 2 shows the change in interception ratio $(\lambda)$ with respect to the length of the unsaturated zone $\left(L_{\mathrm{P}} / L_{0}\right)$ when the hydraulic conductivity of the unsaturated zone is reduced to $1 / 2,1 / 5$ and $1 / 20$ of the initial hydraulic conductivity. In the process of increasing $L_{\mathrm{P}} / L_{0}$ from 0 to $1, \lambda$ increases rapidly in the initial 
Influence of the features of the unsaturated zone on the air injection method in a slope

Xie, Sun, Wei, Shang and Yan

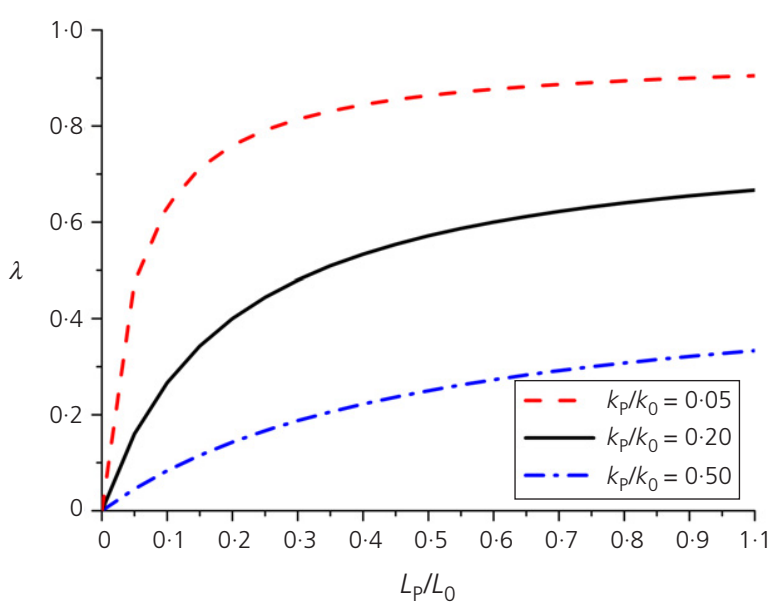

Figure 2. Relationship between interception ratio and the features of the unsaturated zone obtained from Equation 7

stage and then the rate of increase gradually slows. When the decrease in hydraulic conductivity is relatively small, $\lambda$ cannot be increased by substantially increasing the length of the unsaturated zone. As shown in Figure 2 (curve $k_{\mathrm{P}} / k_{0}=0 \cdot 50$ ), even when the length of the unsaturated zone increases to be equal to the length of the recharge zone, the interception ratio is only $0 \cdot 33$. When the decrease in hydraulic conductivity is significant, air injection can obtain a larger interception ratio, even when the length of the unsaturated zone is small. As shown in Figure 2 (curve $k_{\mathrm{P}} / k_{0}=0 \cdot 05$ ), $\lambda$ increases sharply from 0 to 0.63 as $L_{\mathrm{P}} / L_{0}$ increases from 0 to $0 \cdot 1$. However, as the length of the unsaturated zone continues to increase, $\lambda$ does not increase substantially and gradually stabilises. Therefore, the effectiveness of the air injection method in terms of water interception can be improved by increasing the length of the unsaturated zone, but the magnitude of the increase is strongly influenced by the decrease in the hydraulic conductivity of the unsaturated zone.

Equation 7 is simple, but clearly reveals the relationship between two important features of the unsaturated zone (the hydraulic conductivity and the length of the unsaturated zone) and the effectiveness of the air injection method. Equation 7 is based on 2D analysis and certain assumptions, and its accuracy and applicability thus require further study. The influence of the features of the unsaturated zone on the effectiveness of the air injection method was thus analysed using physical model tests and numerical simulations.

\section{Air injection tests and results}

\subsection{Test apparatus and procedure}

As shown in Figure 3, the experimental flume, with a trapezoidal cross-section, was $8 \mathrm{~m}$ long and $1.5 \mathrm{~m}$ deep. The upper part of the flume was $1.5 \mathrm{~m}$ wide, whereas the lower base was $2.5 \mathrm{~m}$ wide. The inclination of the flume was $17^{\circ}$. The two

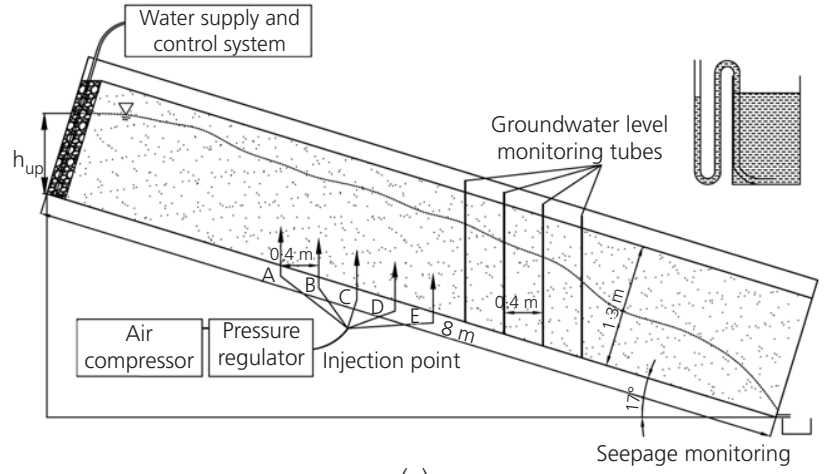

(a)

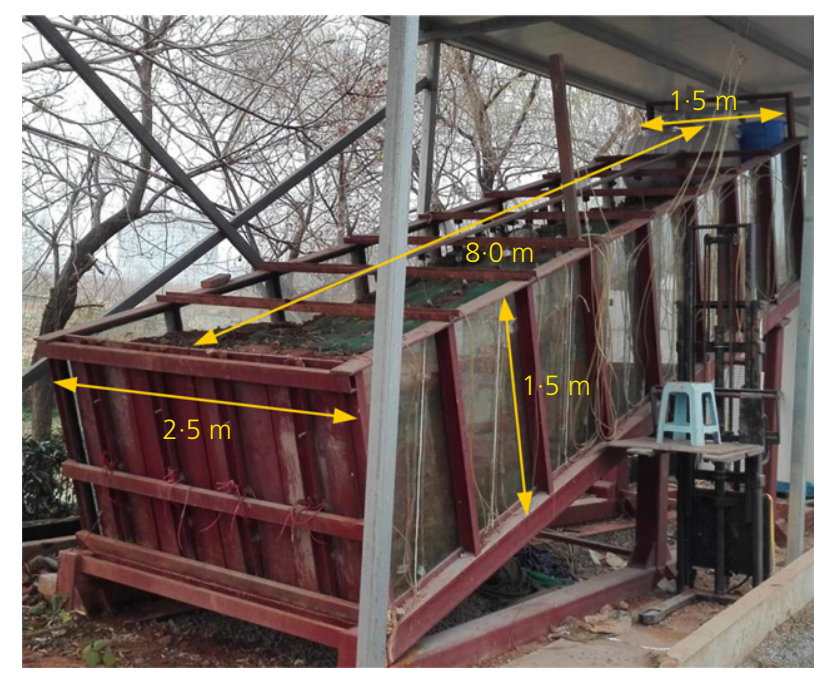

(b)

Figure 3. (a) Schematic illustration of experimental apparatus and (b) experimental flume

side-walls of the flume were made of tempered glass $(20 \mathrm{~mm}$ thick) for the purpose of observing the soil sample during preparation and the slope deformations during the experiments. Steel sections were used on four sides of the flume to guarantee overall stability and sufficient strength. The downstream boundary of the flume was closed by four separate pieces of steel plate with a spacing of $2 \mathrm{~cm}$. Four layers of geotextile were placed before the steel plates to allow the free movement of water from the slope without washing out soil grains. The bottom and side-walls of the slope model flume were impermeable. Water supply equipment was installed at the upstream boundary of the flume and the groundwater level at the upstream boundary of the slope $\left(h_{\mathrm{up}}\right)$ could be adjusted if required. In this paper, the groundwater level refers to the pressure head at a certain point. In other words, it is the vertical distance from the phreatic surface to the bottom of the model flume, instead of the natural ground.

The air supply equipment comprised an air compressor and a pressure regulator. There were five injection points (A-E) 
placed at the centre of the slope model, as shown in Figure 3(a). Point A was placed $2.6 \mathrm{~m}$ from the upstream boundary of the slope and the distance between adjacent injection points was $0.4 \mathrm{~m}$. The air pipe had outside/inside diameters of $8 \mathrm{~mm} / 5 \mathrm{~mm}$ and was carefully surrounded by $0.1 \mathrm{~m}$ of compacted clay to prevent the preferential flow of compressed air along the pipe. The air outlet was placed $5 \mathrm{~cm}$ above the flume bed, and was wrapped tightly in several layers of geotextile to prevent blockage by soil particles.

The model slope was $1.3 \mathrm{~m}$ thick and had a slope angle of $17^{\circ}$. Some $21 \mathrm{~m}^{3}$ of silty clay was used in the model slope. The basic physical and mechanical parameters of the silty clay are provided in Table 1 and Figure 4 shows the grain size distribution. The model slope was prepared using the same compaction procedure in $0.05 \mathrm{~m}$ thick layers of soil to maintain reasonable homogeneity in the slope. In this procedure, the quantity of silty clay for each layer was weighed in advance according to a specific relative density and layer thickness, then placed in the flume and compacted by a hand-held vibratory compactor until the required layer thickness was achieved. The monitoring systems and air supply system were installed in the soil layers during the compaction procedure. To prevent the formation of preferential flow channels along the bottom or side-walls of the model flume, the clay was carefully compacted in a certain range near the bottom and side-walls. Gravel was placed at a longitudinal distance of $0.2 \mathrm{~m}$ from the

\section{Table 1. Soil properties}

\begin{tabular}{lc} 
Parameter & Value \\
\hline Dry density: g/cm & \\
Initial water content: \% & 1.70 \\
Specific gravity & $23 \cdot 30$ \\
Saturated hydraulic conductivity: $\mathrm{cm} / \mathrm{s}$ & 2.73 \\
Cohesion: $\mathrm{kPa}$ & $6 \cdot 59 \times 10^{-4}$ \\
Internal friction angle: degrees & $57 \cdot 80$ \\
& 11.60
\end{tabular}

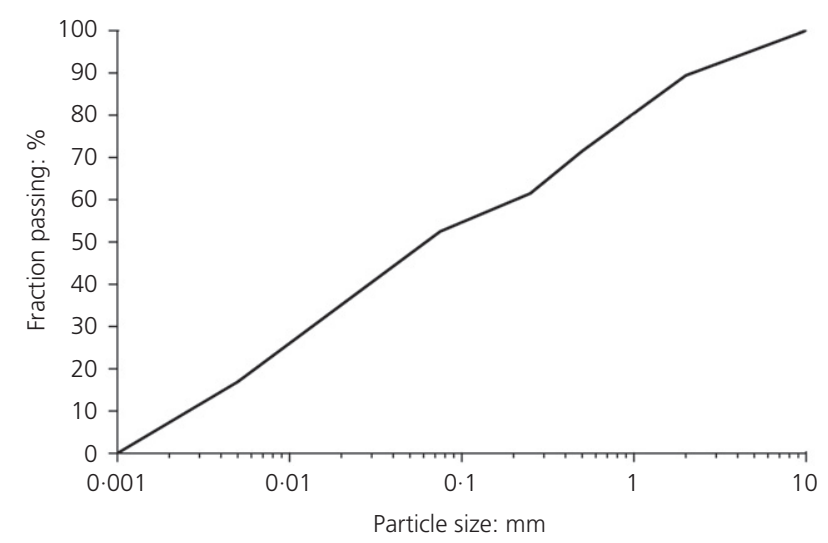

Figure 4. Grain size distribution of the soil used in the physical model upstream end of the flume, and overflow holes were set at a certain height at the upstream boundary of the slope to allow convenient control of the upstream groundwater level.

The groundwater level monitoring equipment was based on the principle of communicating vessels. One end of a U-shaped transparent polyurethane pipe was wrapped in several layers of geotextile and inserted into the bottom of the slope; the other end was fixed to the side-wall of the model flume, as shown in Figure 3(a). The measuring pipes were arranged along the central line of the flume bed in the length direction; the space between adjacent pipes was $0 \cdot 4 \mathrm{~m}$. A water-guiding channel was arranged at the downstream boundary of the slope and the groundwater flowing out from the inside the slope was discharged to a designated position. The seepage from the slope end was obtained by electronically weighing the groundwater from the inside of the slope within a certain period of time.

\subsection{Test procedure}

In total, 16 tests were performed under the experimental conditions summarised in Table 2. The minimum applied injection pressure depended on the sum of hydrostatic pressure from the column of standing water located above the injection point and the capillary pressure arising from the presence of the soil. In the experiments, the minimum injection pressure was estimated by increasing the pressure by a certain amount on the basis of hydrostatic pressure. The test procedure was as follows.

Step 1 . The water supply equipment was started, $h_{\text {up }}=1 \mathrm{~m}$ was maintained and the groundwater table and seepage from the slope end were measured at intervals of approximately $4 \mathrm{~h}$ until these parameters were stable. A series of experiments was performed with initial water depths of $0 \cdot 4,0 \cdot 6,0 \cdot 8,0 \cdot 9,1 \cdot 0$ and $1 \cdot 1 \mathrm{~m}$. The results showed that an input water depth of $1 \cdot 1 \mathrm{~m}$ overflowed onto the surface of the slope, but this did not happen with smaller input water depths. A greater depth of input water corresponds to a higher groundwater level of the slope, making it more convenient to monitor the reduction in downstream groundwater level after air injection. Therefore, an input water depth of $1 \mathrm{~m}$ was selected.

Table 2. Experimental conditions

\begin{tabular}{|c|c|c|c|}
\hline Test & $\begin{array}{c}\text { Injection } \\
\text { pressure, } P: \mathbf{k P a}\end{array}$ & $\begin{array}{l}\text { Length of air } \\
\text { injection, } L \text { : } m\end{array}$ & $\begin{array}{l}\text { Injection } \\
\text { points }\end{array}$ \\
\hline 1 & 21 & $0 \cdot 4$ & $A, B$ \\
\hline 2 & 21 & $0 \cdot 8$ & $A, B, C$ \\
\hline 3 & 21 & $1 \cdot 2$ & $A, B, C, D$ \\
\hline 4 & 21 & 1.6 & $A, B, C, D, E$ \\
\hline 5 & 25 & 0.4 & $A, B$ \\
\hline 6 & 25 & $0 \cdot 8$ & $A, B, C$ \\
\hline 7 & 25 & $1 \cdot 2$ & $A, B, C, D$ \\
\hline 8 & 25 & 1.6 & $A, B, C, D, E$ \\
\hline
\end{tabular}


Step 2. The air compressor was opened, the pressure regulator was adjusted and the injection pressure was gradually increased to the test pressure. The test pressure was maintained for $72 \mathrm{~h}$, during which time the parameters in step 1 continued to be measured. When the monitored values of the groundwater table downslope of the injection point and the seepage from the slope end became constant, the equilibrium condition was assumed to have been reached. The time required to obtain the equilibrium condition varied in each test, but did not exceed $72 \mathrm{~h}$.

- Step 3. The air compressor and water supply equipment were turned off and water at the upstream boundary of the slope was allowed to drain for $5 \mathrm{~d}$. At this point, one air injection test had been completed. Steps 1-3 were then repeated, moving to the next air injection test until all the tests were complete.

\subsection{Test results}

The results showed that the groundwater levels downstream of the slope decreased after implementation of the air injection method. Therefore, air injection can create a relatively stable unsaturated zone as a water interception curtain in a slope, preventing the seepage of upstream groundwater flowing to the potential landslide. However, the effectiveness of the various features of the unsaturated zone in water interception is quite different. In the results discussed below, the length between injection points is taken as the length of the unsaturated zone.

Figure 5 shows the variations in groundwater levels downstream of the injection points after $72 \mathrm{~h}$ of injection at pressures of $21 \mathrm{kPa}$ (tests 1-4) and $25 \mathrm{kPa}$ (tests 5-8). The average decrease in groundwater levels from $4 \cdot 6-7 \cdot 0 \mathrm{~m}$ of the slope for tests $1-4$ was $6 \cdot 4,13 \cdot 0,18 \cdot 7$ and $21 \cdot 3 \%$, respectively, whereas in tests $5-8$, the average decrease in groundwater levels was $12 \cdot 4,22 \cdot 3,25 \cdot 0$ and $27 \cdot 3 \%$, respectively. These results indicate that the groundwater levels continued to fall, albeit at a lower rate, as the number of injection points and length of the unsaturated zone increased. When the length of the air injection increased to a certain value, the groundwater levels in the slope remained basically stable.

Figure 6 shows the variation in the interception ratio with respect to the features of the unsaturated zone. Recall that the length between the injection points was taken as the length of the unsaturated zone, which is a reasonable assumption when the spacing between injection points is small. The data points from tests $1-4$ at $21 \mathrm{kPa}$ can be fitted by the curve obtained from Equation 7 with $k_{0} / k_{\mathrm{P}}=0 \cdot 56$, while the data points from tests $5-8$ at $25 \mathrm{kPa}$ can be fitted by the curve obtained from Equation 7 with $k_{0} / k_{\mathrm{P}}=0.48$. Therefore, the results from the physical tests are in good agreement with the theoretical analysis. Figure 6 indicates that the effectiveness of air injection in terms of water interception is affected by the injection pressure and the arrangement of the injection points. The interception

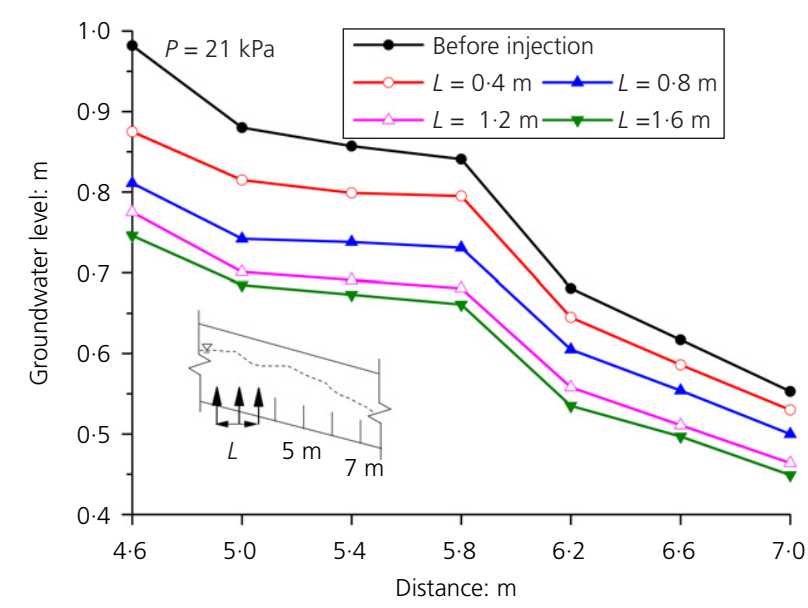

(a)



(b)

Figure 5. Variations in groundwater levels with respect to different features of the unsaturated zone (injection time $72 \mathrm{~h}$ ): (a) tests $1-4, P=21 \mathrm{kPa}$; (b) tests $5-8, P=25 \mathrm{kPa}$

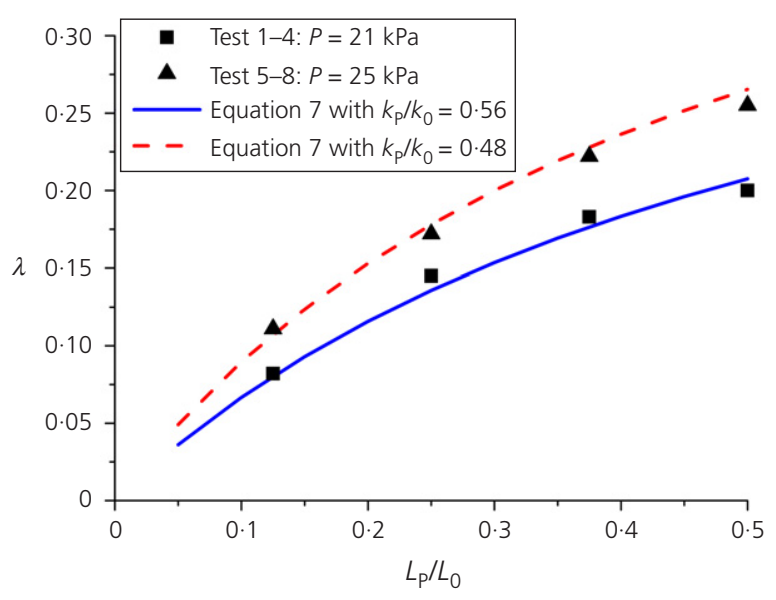

Figure 6. Relationship between interception ratio and the length of the unsaturated zone obtained from physical tests 
ratio increased with an increase in the length of the unsaturated zone. This increase was large in the early stages, but relatively small in the later stages. For the same length of the unsaturated zone, a higher injection pressure produced a higher interception ratio. This is because a higher injection pressure further decreases the degree of saturation, leading to a decrease in hydraulic conductivity.

\section{Numerical simulations of the development of the unsaturated zone with multiple injection points}

The complicated pore structure of soil and the continuous variation of the air-water interface make it difficult to observe the movement of fluids directly during air injection. Expansion of the unsaturated zone in a slope is a very complicated process and the length of the unsaturated zone is difficult to determine accurately. In the physical model tests described in Section 3, the length of the unsaturated zone was not exact but was determined based on a simplifying assumption. Considering the complexity of multi-phase seepage in porous media, numerical simulations are useful analysis tools. Therefore, numerical analysis based on Geostudio (geoengineering finite-element software) was used to further explore the length variation of the unsaturated zone with respect to the number of injection points and its effect on the interception ratio. In the Seep/W and Air/W modules in Geostudio (Geoslope, 2007a, 2007b), the governing differential equations for the flow of water and air in soil used for complete analysis of 2D seepage are

8. $m_{\mathrm{w}} \gamma_{\mathrm{w}} \frac{\partial H_{\mathrm{w}}}{\partial t}=\frac{\partial}{\partial y}\left[k_{\mathrm{w}} \frac{\partial H_{\mathrm{w}}}{\partial y}\right]+m_{\mathrm{w}} \frac{\partial u_{\mathrm{a}}}{\partial t}+Q_{\mathrm{w}}$

9.

$$
\begin{aligned}
\left(\frac{\theta_{\mathrm{a}}}{R T}+\rho_{\mathrm{a}} m_{\mathrm{w}}\right) \frac{\partial u_{\mathrm{a}}}{\partial t}= & \frac{\partial}{\partial y}\left[\frac{\rho_{\mathrm{a}} k_{\mathrm{a}}}{\gamma_{\mathrm{aa}}} \frac{\partial u_{\mathrm{a}}}{\partial y}+\frac{\rho_{\mathrm{a}}^{2} k_{\mathrm{a}}}{\rho_{\mathrm{oa}}}\right] \\
& -\frac{\theta_{\mathrm{a}} u_{\mathrm{a}}}{R} \frac{\partial(1 / T)}{\partial t}+\rho_{\mathrm{a}} \gamma_{\mathrm{w}} m_{\mathrm{w}} \frac{\partial H_{\mathrm{w}}}{\partial t}
\end{aligned}
$$

where $m_{\mathrm{w}}$ is the slope of the volumetric water content function, $\gamma_{\mathrm{w}}$ is the unit weight of water, $k_{\mathrm{w}}$ is hydraulic conductivity, $H_{\mathrm{w}}$ is the total head of water, $u_{\mathrm{a}}$ is the pore air pressure, $Q_{\mathrm{w}}$ is the applied water boundary flux, $\theta_{\mathrm{a}}$ is the volumetric air content, $R$ is a constant of $287 \mathrm{~J} /(\mathrm{kg} . \mathrm{K}), T$ is the temperature, $\gamma_{\mathrm{oa}}$ is the unit weight of air in dry conditions and $\rho_{\mathrm{oa}}$ is the density of air in dry conditions.

The soil-water characteristic curve and the water permeability are estimated using Equations 10 and 11 (Van Genuchten, 1980), respectively, and the air permeability function is estimated by Equation 12 (Brooks and Corey, 1964).

10. $\theta_{\mathrm{w}}=\theta_{\mathrm{r}}+\frac{\theta_{\mathrm{s}}-\theta_{\mathrm{r}}}{\left[1+(a \phi)^{n}\right]^{m}}$
11. $k_{\mathrm{w}}=k_{\mathrm{s}} \frac{\left\{1-(a \phi)^{n-1}\left[1+(a \phi)^{n}\right]^{-m}\right\}^{2}}{\left[1+(a \phi)^{n}\right]^{m / 2}}$

12. $k_{\mathrm{a}}=k_{\mathrm{dry}}\left(1-S_{\mathrm{w}}\right)^{0.5}\left(1-S_{\mathrm{w}}^{1 / q}\right)^{2 q}$

Here, $\theta_{\mathrm{r}}$ is the residual volumetric water content, $\theta_{\mathrm{s}}$ is the saturated volumetric water content, $\phi$ is the matric suction (which is the difference between the pore air and the pore water pressures $\left.\left(\phi=u_{\mathrm{a}}-u_{\mathrm{w}}\right)\right), k_{\mathrm{s}}$ is the saturated hydraulic conductivity, $k_{\mathrm{a}}$ is the estimated air conductivity at a particular degree of saturation, $k_{\text {dry }}$ is the air conductivity of the dry soil, $S_{\mathrm{w}}$ is the degree of saturation of the soil, $a, m$ and $n$ are curve fitting parameters and $q$ is an empirical constant depending on the type of soil. $a$ is approximately equal to the air-entry pressure, while $n$ and $m$ are related to the pore size distribution and the overall symmetry of the soil-water characteristic curve of the soil. The parameter $m$ is frequently constrained by some direct relation to $n$, such as $n=1 /(1-m)$. Referring to previous research results (Lu and Likos, 2004; Van Genuchten, 1980), values of $a=12 \mathrm{kPa}, n=1.76, m=0.43$ and $q=2.9$ were used in the simulations.

The computational model is shown in Figure 7 and Table 3 lists the parameters used in the numerical simulations. The meshing pattern was a mixed quadrilateral and triangular mesh. The size of the elements was approximately $0 \cdot 1 \mathrm{~m}$. First, a steady analysis with $\mathrm{Seep} / \mathrm{W}$ was performed to obtain the initial conditions for subsequent transient analysis with Seep/W and Air/W. For the transient analysis, the time step was $1 \mathrm{~h}$ and this was increased linearly. Two injection pressures were applied in the numerical simulations, $25 \mathrm{kPa}$ and $32 \mathrm{kPa}$. The injection time was $72 \mathrm{~h}$. There were five injection points (A-E) as shown in Figure 7. Point A was placed $2.6 \mathrm{~m}$ from the upstream boundary of the slope model and the distance between adjacent injection points was $0.4 \mathrm{~m}$. Ten simulations were conducted and the number of injection points increased from one to five in the first to fifth simulations.

Figure 8 compares the variations in groundwater levels in the physical model test with those given by the numerical simulations. The results of the numerical simulations were very close to those obtained in the physical tests and the numerical predictions were in reasonable agreement with the laboratory data.

Figure 9 shows the expansion of the unsaturated zone with an increase in the number of injection points. The expansion of the inner red zone in Figure 9 represents the development of the unsaturated zone, where saturation was reduced by more than $30 \%$. The length of the unsaturated zone formed by one single injection point is a fixed value and the shape of the unsaturated zone is approximately elliptical in the $2 \mathrm{D}$ plane. As shown in Figure 9, the length of the unsaturated zone 


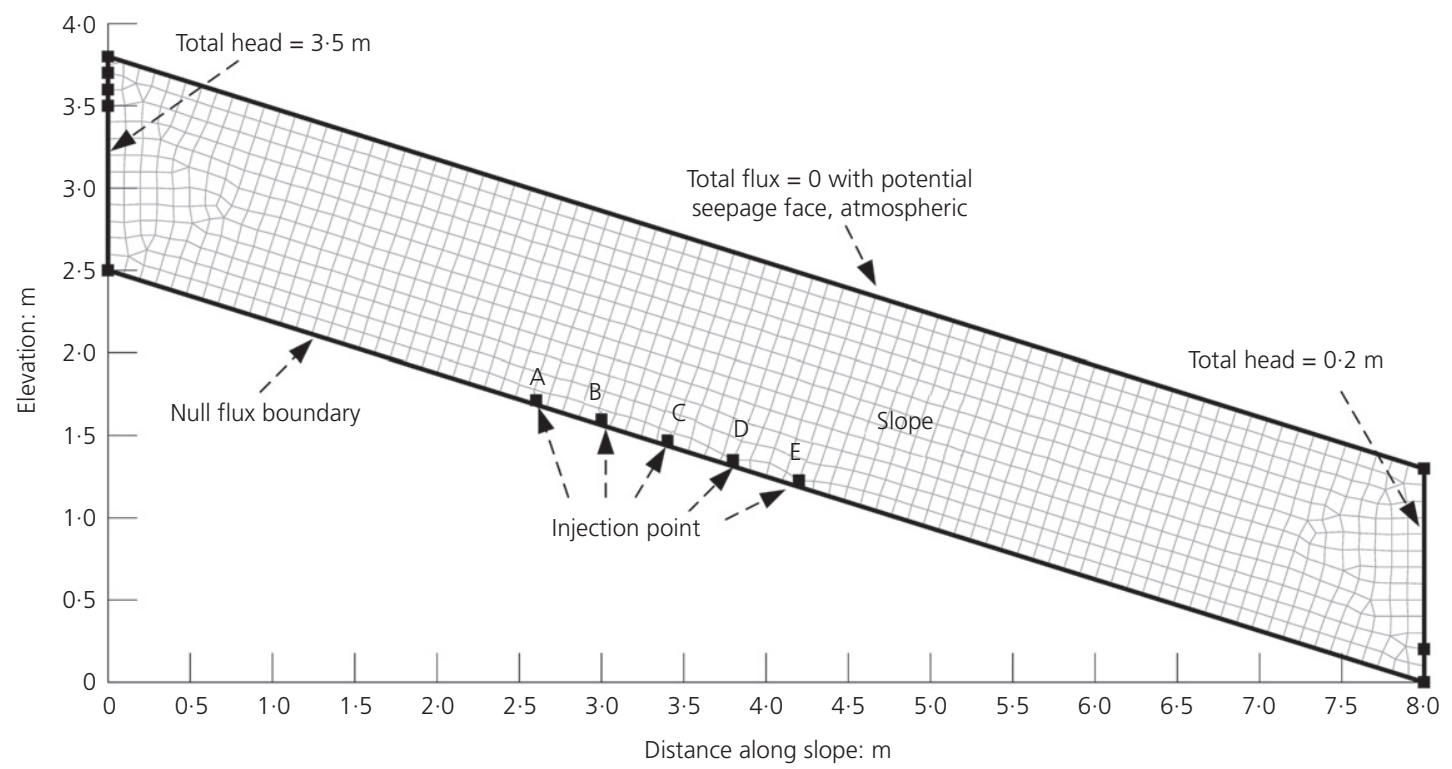

Figure 7. Computational model of air injection in the slope

Table 3. Parameters used in the numerical analysis of the slope

\begin{tabular}{ll} 
Parameter & \multicolumn{1}{c}{ Value } \\
\hline Saturated hydraulic conductivity, $k_{\mathrm{s}}: \mathrm{m} / \mathrm{s}$ & $1.04 \times 10^{-5}$ \\
Dry soil air conductivity, $k_{\text {dry }}: \mathrm{m} / \mathrm{s}$ & $2.08 \times 10^{-4}$ \\
Saturated volumetric water content, $\theta_{\mathrm{s}}: \mathrm{m}^{3} / \mathrm{m}^{3}$ & 0.43 \\
Residual volumetric water content, $\theta_{\mathrm{r}}: \mathrm{m}^{3} / \mathrm{m}^{3}$ & 0.05
\end{tabular}

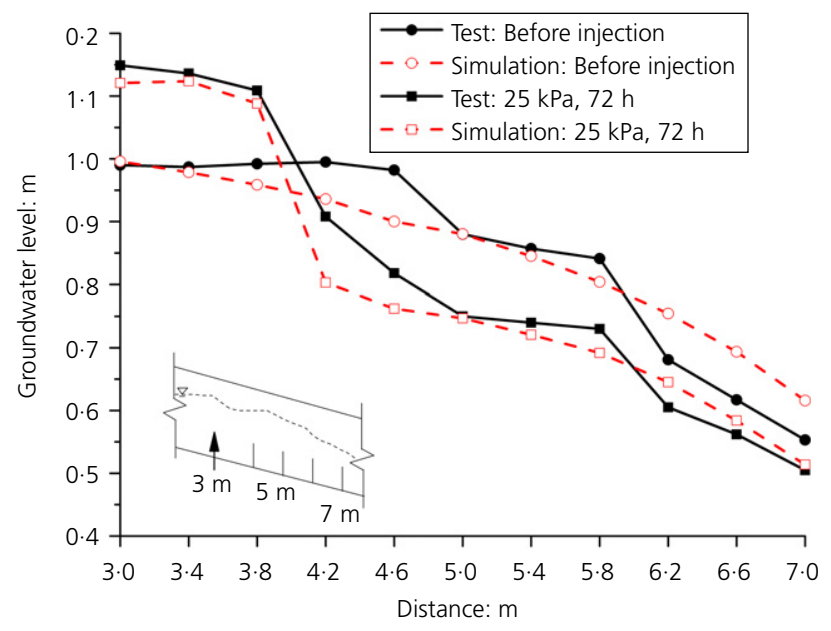

Figure 8. Variations in groundwater levels in physical model tests and numerical simulations

formed by multiple injection points is not a simple superposition of the unsaturated zones formed by one single injection point and the expansion in its length is not symmetrical but tends toward the downstream direction.
Figure 10 shows the variation in the interception ratio with respect to the length of the unsaturated zone obtained in the numerical simulations. For an injection pressure of $32 \mathrm{kPa}$ and two injection points $0.4 \mathrm{~m}$ apart, the dimension of the unsaturated zone was $L_{\mathrm{P}} / L_{0}=0.39$ and the interception ratio was 0.49 after $72 \mathrm{~h}$ injection. With an increase in the length of the unsaturated zone, Figure 10 indicates that the effectiveness of the air injection in terms of water interception did not increase proportionally. The data points can be fitted by the curve obtained from Equation 7 with $k_{0} / k_{\mathrm{P}}=0 \cdot 25$. Therefore, the numerical simulations were in good agreement with the theoretical analysis. The numerical analysis showed that the interception ratio increased rapidly with the initial increase in the length of the unsaturated zone and then gradually stabilises.

The characteristics of the unsaturated zone formed by air injection are critical to the design of the method. This analysis showed that when the hydraulic conductivity of the unsaturated zone decreases by a certain amount, an increase in the length of the unsaturated zone causes the interception ratio to increase quickly in the initial stage, before the rate of increase gradually slows and the interception ratio stabilises. The value of the stable interception ratio depends on the decline in the hydraulic conductivity of the unsaturated zone. The basic feature of the variation in the interception ratio is of great significance for the design of the air injection method. This indicates that the range of lengths of the unsaturated zone that can significantly improve the interception ratio is limited. If the length of the unsaturated zone exceeds this range, the interception ratio should be increased by reducing the hydraulic conductivity of the unsaturated 


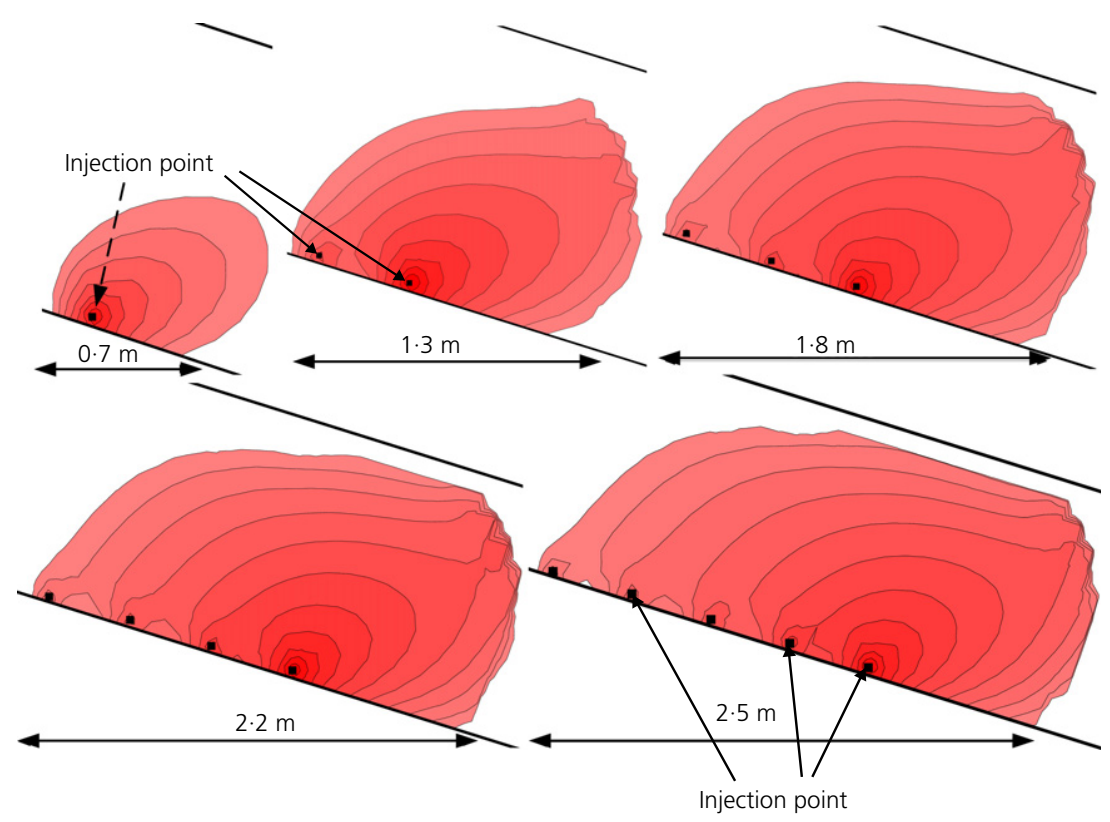

Figure 9. Expansion of the unsaturated zone with respect to the number of injection points $(P=32 \mathrm{kPa})$

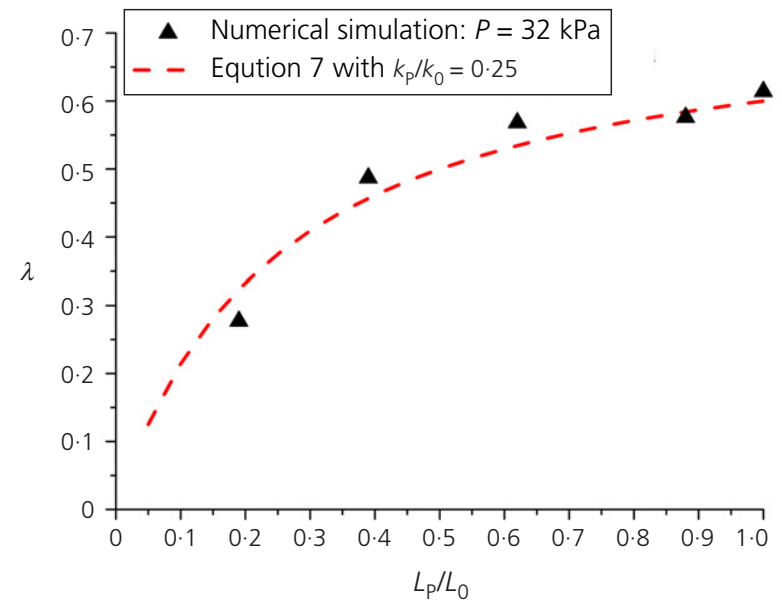

Figure 10. Relationship between interception ratio and the length of the unsaturated zone obtained from numerical simulations

zone rather than by increasing the length of the unsaturated zone.

For shallow slope failures caused by the formation of a saturated zone, air injection near the surface can expel groundwater and significantly reduce infiltration on the slope surface. For slope failures caused by a rising groundwater table, air injection underneath the slope can act as a waterproof curtain owing to its low permeability, thus controlling the rapid rise in the groundwater level. Both of these factors are important for the air injection method. Further research will be conducted on the effect of air injection near the surface. The equipment required for the air injection method simply comprises air compressors, geological drilling rigs, power supply facilities and so on, which can be easily obtained and operated in the field. Therefore, the air injection method is expected to provide a fresh perspective on slope drainage and to serve as a crisis management technique for landslide mitigation.

\section{Conclusion}

The effects of the features of the unsaturated zone on the air injection method were investigated based on theoretical analysis, physical model tests and numerical simulations. Air injection divides a slope into three zones: a groundwater recharge zone, an unsaturated zone and a groundwater control zone. The length and hydraulic conductivity of the unsaturated zone are the two main parameters that characterise the unsaturated zone. The interception ratio was defined to evaluate the effectiveness of the air injection method in intercepting groundwater. The simplified theoretical relationship between the interception ratio and the characteristics of the unsaturated zone shows that the interception ratio is affected by both the permeability and the length of the unsaturated zone. The effectiveness of the air injection method can be enhanced by increasing the length of the unsaturated zone, but the magnitude of the enhancement is strongly influenced by any decrease in hydraulic conductivity. The results of the physical tests and numerical simulations were found to be in good agreement with the theoretical analysis. These results indicate that the interception ratio increases rapidly with the initial increase in the length of the unsaturated zone and then gradually stabilises. The variation in the interception ratio is of great significance for the design of the air injection method. 


\section{Acknowledgements}

This research was financially supported by the National Natural Science Foundation of China (no. 41372277) and Key R\&D projects of Zhejiang Province (no. 2017C03006).

\section{REFERENCES}

Allenby D and Kilburn D (2015) Overview of underpinning and caisson shaft-sinking techniques. Proceedings of the Institution of Civil Engineers - Geotechnical Engineering 168(1): 3-15, https://doi.org/10.1680/geng.13.00117.

Brooks RJ and Corey AT (1964) Hydraulic Properties of Porous Media. Colorado State University, Fort Collins, CO, USA, Hydrology Paper No. 3.

Budhu M (2010) Soil Mechanics and Foundations, 3rd edn. Wiley, Hoboken, NJ, USA

Castelletto N, Ferronato M, Gambolati G et al. (2013) Can natural fluid pore pressure be safely exceeded in storing gas underground? Engineering Geology 153: 35-44, https://doi.org/10.1016/ j.enggeo.2012.11.008.

Catney SF and Lynch RJ (2001) Experimental investigations of air sparging to control contaminated groundwater. Proceedings of the Institution of Civil Engineers - Geotechnical Engineering 149(4): 253-258, https://doi.org/10.1680/geng.2001.149.4.253.

Cotecchia F, Lollino P and Petti R (2016) Efficacy of drainage trenches to stabilise deep slow landslides in clay slopes. Géotechnique Letters 6(1): 1-6, https://doi.org/10.1680/jgele.15.00065

Du L, Sun H and Shang Y (2013) Air-filled drainage method in loose accumulation soil slope. Journal of Jilin University (Earth Science Edition) 43(3): 877-882

Fredlund DG (2006) Unsaturated soil mechanics in engineering practice. Journal of Geotechnical and Geoenvironmental Engineering 132(3): 286-321, https://doi.org/10.1061/(Asce)1090-0241(2006)132:3(286).

Geoslope (2007a) Air Flow Modeling with Air/W 2007. Geoslope, Calgary, Alberta, Canada.

Geoslope (2007b) Seepage Modeling with Seep/W 2007. Geoslope, Calgary, Alberta, Canada

Liu C, Sun H, Kang J and Du L (2014) Experimental investigation of seepage barrier effect by air-inflation in soil. Journal of Zhejiang University (Engineering Science) 48(02): 236-241, https://doi.org/ 10.3785/j.issn.1008-973X.2014.02.008.

Lu N and Likos WJ (2004) Unsaturated Soil Mechanics. Wiley, New York, NY, USA

Lundegard PD and Andersen G (1996) Multiphase numerical simulation of air sparging performance. Ground Water 34(3): 451-460, https://doi.org/10.1111/j.1745-6584.1996.tb02026.x.

Nakajima T, Saito H, Tojo S and Hu QH (2016) Effects of confining pressure on unsteady-state air permeability measurement method in an aggregated andisol. Vadose Zone Journal 15(3): 1-9, https://doi.org/10.2136/vzj2015.05.0081

Neyshabouri MR, Rahmati M, Doussan C and Behroozinezhad B (2013) Simplified estimation of unsaturated soil hydraulic conductivity using bulk electrical conductivity and particle size distribution. Soil Research 51(1): 23-33, https://doi.org/ $0.1071 / \mathrm{Sr} 12158$

Okamura M, Takebayashi M, Nishida K et al. (2011) In situ desaturation test by air injection and its evaluation through field monitoring and multiphase flow simulation. Journal of Geotechnical and Geoenvironmental Engineering 137(7): 643-652.

Rahardjo H, Hritzuk KJ, Leong EC and Rezaur RB (2003) Effectiveness of horizontal drains for slope stability. Engineering Geology 69(3-4): 295-308, https://doi.org/10.1016/s0013-7952(02)00288-0.

Schuster RL and Highland LM (2007) The third Hans Cloos lecture. Urban landslides: socioeconomic impacts and overview of mitigative strategies. Bulletin of Engineering Geology and the Environment 66(1): 1-27, https://doi.org/10.1007/s10064006-0080-z.

Semer R, Adams J and Reddy KR (1998) An experimental investigation of air flow patterns in saturated soils during air sparging. Geotechnical and Geological Engineering 16(1): 59-75.

Sun $\mathrm{H}$ and Shang Y (2009) A New Drainage Method for Landslide Mitigation: the Air Injection Method. Chinese Patent ZL200910099603.0, Nov.

Sun H, Wong LNY, Shang Y, Shen Y and Lue Q (2010) Evaluation of drainage tunnel effectiveness in landslide control. Landslides 7(4): 445-454, https://doi.org/10.1007/s10346-010-0210-3.

Van Genuchten MT (1980) A closed form equation predicting the hydraulic conductivity of unsaturated soils. Soil Science Society of America Journal 44(5): 892-898, https://doi.org/10.2136/sssaj1980. $03615995004400050002 x$.

Xie W, Shang Y, Lu Q, Jiang H and Wei Z (2018a) Experimental study of groundwater level variation in soil slope using air-injection method. Géotechnique Letters 8(2): 144-148, https://doi.org/ 10.1680/jgele.18.00005.

Xie W, Shang Y, Wu G and Wei Z (2018b) Investigation of the formation process of a low-permeability unsaturated zone by air injection method in a slope. Engineering Geology 245: 10-19, https://doi.org/ 10.1016/j.enggeo.2018.08.005.

Zeybek A and Madabhushi GSP (2018) Physical modelling of air injection to remediate liquefaction. International Journal of Physical Modelling in Geotechnics 18(2): 68-80, https://doi.org/ 10.1680/jphmg.16.00049.

Zhan TLT, Yang YB, Chen R, Ng CWW and Chen YM (2014) Influence of clod size and water content on gas permeability of a compacted loess. Canadian Geotechnical Journal 51(12): 1468-1474, https://doi.org/10.1139/cgj-2014-0126.

Zhang F and Fredlund DG (2015) Examination of the estimation of relative permeability for unsaturated soils. Canadian Geotechnical Journal 52(12): 2077-2087, https://doi.org/10.1139/cgj-2015-0043.

Zhang LL, Zhang J, Zhang LM and Tang WH (2011) Stability analysis of rainfall-induced slope failure: a review. Proceedings of the Institution of Civil Engineers - Geotechnical Engineering 164(5): 299-316, https://doi.org/10.1680/geng.2011.164.5.299.

Zhou AN, Li CQ and Huang JS (2016) Failure analysis of an infinite unsaturated soil slope. Proceedings of the Institution of Civil Engineers - Geotechnical Engineering 169(5): 410-420, https://doi.org/10.1680/jgeen.15.00172.

\section{How can you contribute?}

To discuss this paper, please email up to 500 words to the editor at journals@ice.org.uk. Your contribution will be forwarded to the author(s) for a reply and, if considered appropriate by the editorial board, it will be published as discussion in a future issue of the journal.

Proceedings journals rely entirely on contributions from the civil engineering profession (and allied disciplines). Information about how to submit your paper online is available at www.icevirtuallibrary.com/page/authors, where you will also find detailed author guidelines. 